\title{
Tidal volume monitoring during emergency neonatal transport
}

\author{
Joanna D. Costa ${ }^{1}$ Sandeep Sadashiv ${ }^{2}$ Jennifer Hesler ${ }^{3} \cdot$ Robert G. Locke ${ }^{4}$ Thomas J. Blackson ${ }^{4} \cdot$ Amy B. Mackley $^{4}$
}

Received: 15 February 2018 / Revised: 6 September 2018 / Accepted: 11 September 2018 / Published online: 5 October 2018

(c) Springer Nature America, Inc. 2018

\begin{abstract}
Objective The study aim was to identify the frequency with which tidal volumes were achieved in a target range in infants requiring positive pressure ventilation on emergency transport.

Study design We performed a prospective observational study of infants requiring continued positive pressure ventilation during emergency transport after resuscitation and stabilization. Blindly recorded data were analyzed for percentage of breaths that were below range, in range, and above desired range of $4-6 \mathrm{~mL} / \mathrm{kg}$.

Result Fourteen patients were monitored during transport from the delivery room to the neonatal intensive care unit, and 15 patients were monitored during inter-facility transport. During delivery room transport, 21 and $7 \%$ of patients were in target range greater than 50 and $90 \%$ of the time, respectively. During inter-hospital transport, 60 and $7 \%$ of patients were in target range greater than 50 and $90 \%$ of the time, respectively.

Conclusion Clinical assessment of appropriate ventilation is difficult and often inaccurate during emergency neonatal transport. Improved monitoring of respiratory function to guide clinical status during transport is necessary. More investigation and implementation are urgently needed.
\end{abstract}

\section{Introduction}

Approximately $5-10 \%$ of all neonates, and the majority of premature infants younger than 30 weeks' gestation, require resuscitation that includes positive pressure ventilation at birth. Effective positive pressure ventilation is necessary to resuscitate almost all apneic or bradycardic newborns. However, positive pressure ventilation has the potential to cause harm through mechanisms of volutrauma and atelectrauma that lead to long-lasting changes in the lungs. In an animal model, as few as six large manual breaths were sufficient to cause histologic lung injury. Excessive tidal volumes lead to hypocarbia, which can induce alkalosis, worsen bronchopulmonary dysplasia, and reduce cardiac output [1-4]. Hypocarbia has also been associated with

Joanna D. Costa

joanna.costa@nemours.org

1 Nemours/Alfred I. duPont Hospital for Children, Wilmington, DE, USA

2 Einstein Medical Center Montgomery, East Norriton, PA, USA

3 Children's Hospital of Philadelphia, Chester County Hospital, West Chester, PA, USA

4 Christiana Care Health Systems, Newark, DE, USA periventricular leukomalacia, hearing impairment, and cerebral palsy. Inadequate ventilation, on the other hand, can result in hypercarbia, which has been linked to intraventricular hemorrhage and acidosis [5]. As a result, there is increasing attention during neonatal resuscitation to using lung-protective strategies.

Following delivery room resuscitation and stabilization, infants who continue to require positive pressure ventilation are transferred from the delivery room to the neonatal intensive care unit (NICU) in a transport incubator. Furthermore, approximately $1 \%$ of newborn infants require inter-hospital transport for continuation of higher-level care. In transport from the delivery room, positive pressure ventilation is provided by manual ventilation using a flowinflating bag, a self-inflating bag, or T-piece device. Portable ventilators are commonly used for respiratory support during inter-hospital transport of critically ill neonates. In recent years, increasingly sophisticated in-line measurement tools of lung function have improved management of mechanical ventilation and have become the standards of care in the NICU. However, these techniques have not been universally applied during intra- or inter-facility transport of neonates, and providers continue to rely on clinical signs as estimates of adequate ventilation. Tracy et al. demonstrated that clinical estimates of ventilator settings are unreliable in attaining normocarbia and normoxia on arrival of a patient 
in the NICU and that dynamic lung function monitoring during transport contributes to greater achievement of these parameters [6].

Breaths during transport are delivered either manually or mechanically by a targeted peak inspiratory pressure (PIP). However, the optimal PIP to deliver is unknown, with users starting with pressures ranging from 20 to $30 \mathrm{~cm} \mathrm{H}_{2} \mathrm{O}$ [7]. These same pressures are generally maintained during transport of the neonate, but little is actually understood regarding the tidal volumes that are delivered at this critical time of newborn transition. During this time period, there is unpredictable variability in the infant's pulmonary mechanics, with dynamic changes in compliance and volume-pressure relationships. Clinical assessments of the adequacy of ventilation are limited to the heart rate, observation of chest wall movement, and $\mathrm{SpO}_{2}$ monitoring and have been shown to be imprecise. Dynamic lung function monitoring during transport contributes to greater achievement of these parameters [6].

We performed a study of infants requiring positive pressure ventilation on transport, both from the delivery room to the NICU and from referring facilities to our level III NICU, examining the frequency with which tidal volumes were achieved in a range of $4-6 \mathrm{~mL} / \mathrm{kg}$, as well as below or above the target range.

\section{Materials and methods}

\section{Human subject protection}

The study was approved by the Christiana Care Hospital Institutional Review Board (IRB). The IRB approved waiver of consent for this study.

\section{Delivery room to NICU transport}

High-risk deliveries at Christiana Care Hospital are routinely attended by a combination of neonatologists, neonatal fellows, neonatal nurse practitioners, pediatric residents, pediatric hospitalists, and NICU nursing and respiratory staff.

The Fisher-Paykel Healthcare Neopuff Infant Resuscitator (Auckland, NZ) infant resuscitator is used in delivery room resuscitation of all newborns. Resuscitation is routinely initiated with standardized Neopuff settings with PIP of $20 \mathrm{~cm} \mathrm{H}_{2} \mathrm{O}$ and positive end-expiratory pressure (PEEP) of $5 \mathrm{~cm} \mathrm{H}_{2} \mathrm{O}$. Settings are adjusted at the discretion of the provider to achieve desired ventilation and oxygenation as determined by chest rise and $\mathrm{SpO}_{2}$ measurements.

All inborn infants who required intubation and positive pressure ventilation during delivery room resuscitation were included in the study. During transport from the delivery room to the NICU, infants were manually ventilated using the Neopuff resuscitator. Again, initial PIP during resuscitation was standardized to $20 \mathrm{~cm} \mathrm{H}_{2} \mathrm{O}$ and PEEP to $5 \mathrm{~cm}$ $\mathrm{H}_{2} \mathrm{O}$, with PIP increased by provider to achieve desired ventilation and oxygenation as determined by chest rise and oxygenation.

Lung function measurements were recorded using the Philips Respironics NM3 Respiratory Profile Monitor (Amsterdam, Netherlands) and an in-line flow sensor (Philips $\mathrm{CO}_{2} /$ Flow Sensor Neonatal) secured to a delivery room transporter. Providers performing manual ventilation were blinded to the monitor, which was installed on the transporter out of sight. Data were recorded on the monitor, including minute-to-minute tidal volume, respiratory rate, PIP, PEEP, and mean airway pressure, and analyzed. Demographic data were also collected on all enrolled patients.

\section{Inter-hospital transport}

All out-born neonatal patients requiring transport to Christiana Care Hospital are transported by a dedicated neonatal transport team consisting of a neonatal fellow, neonatal nurse practitioner, or pediatric hospitalist, in addition to NICU nursing and respiratory staff.

Neonates who require it receive mechanical ventilatory support on transport. The transport ventilator used in the study was the MVP-10 by Bio-Med Devices (Guilford, CT). Routinely, standard PIP and PEEP are initiated at $20 \mathrm{~cm}$ $\mathrm{H}_{2} \mathrm{O}$ and $5 \mathrm{~cm} \mathrm{H}_{2} \mathrm{O}$, respectively, and adjusted by the provider to achieve desired ventilation and oxygenation as determined by available blood gas data before transport, chest radiograph appearance, and oxygenation based on $\mathrm{SpO}_{2}$ measurements. Real-time feedback provided by current routine monitoring on transport includes respiratory rate, heart rate, and $\mathrm{SpO}_{2}$.

For patients enrolled in the study, lung function measurements were recorded using the Philips Respironics NM3 Respiratory Profile Monitor and an in-line flow sensor (Philips $\mathrm{CO}_{2} /$ Flow Sensor Neonatal) secured to a neonatal transporter. Providers were blinded to the monitor. Data were recorded on the monitor, including minute-to-minute tidal volume, respiratory rate, PIP, PEEP, and mean airway pressure, and analyzed. Demographic data were also collected on all enrolled patients.

\section{Analysis}

Recorded data were analyzed for percentage of breaths that were below range, in range, and above desired range of 4-6 $\mathrm{mL} / \mathrm{kg}$. 
Table 1 Neonates receiving manual positive pressure ventilation during delivery room-to-NICU transport

\begin{tabular}{|c|c|c|c|c|c|c|c|c|}
\hline \multirow[t]{2}{*}{ Subject } & \multirow{2}{*}{$\begin{array}{l}\text { Birth gestational age } \\
\text { (weeks) }\end{array}$} & \multirow{2}{*}{$\begin{array}{l}\text { Weight } \\
(\mathrm{kg})\end{array}$} & \multirow{2}{*}{$\begin{array}{l}\text { Length of transport } \\
\text { (min) }\end{array}$} & \multirow{2}{*}{$\begin{array}{l}\text { Mean PIP on } \\
\text { transport } \\
(\mathrm{cm} \mathrm{H} 20)\end{array}$} & \multirow{2}{*}{$\begin{array}{l}\text { Respiratory rate total/ } \\
\text { mechanical } \\
\text { (breaths/minute) }\end{array}$} & \multicolumn{3}{|c|}{ Goal tidal volume $4-6 \mathrm{ml} / \mathrm{kg}$} \\
\hline & & & & & & $\begin{array}{l}<4 \mathrm{ml} / \mathrm{kg} \\
(\%)\end{array}$ & $\begin{array}{l}4-6 \mathrm{ml} / \mathrm{kg} \\
(\%)\end{array}$ & $\begin{array}{l}>6 \mathrm{ml} / \mathrm{kg} \\
(\%)\end{array}$ \\
\hline 1 & 25.2 & 0.88 & 8 & 14 & $42 / 21$ & 0 & 100 & 0 \\
\hline 2 & 24.5 & 0.6 & 10 & 17 & $50 / 47$ & 0 & 0 & 100 \\
\hline 3 & 41 & 3.7 & 12 & 19 & $70 / 53$ & 58 & 42 & 0 \\
\hline 4 & 26 & 1.08 & 10 & 17 & $34 / 23$ & 100 & 0 & 0 \\
\hline 5 & 29.5 & 0.905 & 8 & 17 & $29 / 24$ & 0 & 13 & 88 \\
\hline 6 & 26.2 & 0.94 & 9 & 22 & $51 / 41$ & 0 & 22 & 78 \\
\hline 7 & 36 & 3.04 & 8 & 21 & $58 / 41$ & 25 & 75 & 0 \\
\hline 8 & 29 & 1.15 & 9 & 19 & $68 / 47$ & 22 & 78 & 0 \\
\hline 9 & 34.2 & 1.4 & 12 & 22 & $32 / 30$ & 0 & 8 & 92 \\
\hline 10 & 29.4 & 1.07 & 9 & 12 & $37 / 19$ & 0 & 33 & 67 \\
\hline 11 & 39.2 & 3.55 & 11 & 8 & $75 / 20$ & 9 & 0 & 91 \\
\hline 12 & 33.2 & 2.04 & 8 & 26 & $39 / 37$ & 0 & 0 & 100 \\
\hline 13 & 28 & 1.24 & 12 & 15 & $44 / 28$ & 0 & 0 & 100 \\
\hline 14 & 28 & 0.95 & 9 & 19 & $62 / 44$ & 0 & 0 & 100 \\
\hline Mean & 30.7 & 1.6 & 9.6 & 18 & & & & \\
\hline
\end{tabular}

\section{Results}

\section{Delivery room to NICU transport}

A total of 14 patients were monitored during transport from the delivery to the NICU. They ranged in gestational age from 24 weeks 5 days to 41 weeks (mean 31 weeks). Birth weight ranged from $0.6 \mathrm{~kg}$ grams to $3.55 \mathrm{~kg}$ (mean $1.6 \mathrm{~kg}$ ). The length of transport ranged from 8 to 12 min (mean 10 min). Only 1 patient of $14(7 \%)$ was in range greater than $90 \%$ of the time. Three of 14 patients $(21 \%)$ were in the target range greater than $50 \%$ of the time. Six of 14 patients (43\%) were above the target range greater than $90 \%$ of the time, and 9 of the $14(64 \%)$ patients were above the target range greater than $50 \%$ of the time (Table 1).

\section{Inter-hospital transport}

A total of 15 patients were monitored during transport from referring facilities to Christiana Care Hospital. They ranged from gestational age at birth of 26 weeks to 40 weeks (mean 34 weeks) and corrected gestational age at the time of transport of 26 weeks to 40 weeks (mean 35 weeks). They ranged in weight at the time of transport from $0.92 \mathrm{~kg}$ to $3.57 \mathrm{~kg}$ (mean $2.48 \mathrm{~kg}$ ). The length of transport ranged from 26 min to 214 min (mean $77 \mathrm{~min}$ ). Only one patient $(7 \%)$ was in the target range for achieved tidal volume greater than $90 \%$ of the time. Nine of 15 patients $(60 \%)$ were in the target range greater than $50 \%$ of the time. Three of 15 patients (20\%) were either below or above the target range greater than $50 \%$ of the time (Table 2).

\section{Discussion}

These findings demonstrate that the use of fixed pressurelimited assisted ventilation devices in critically ill infants requiring transport to a NICU may result in variable and frequently out-of-target-range tidal volume delivery. In both cases of delivery room and inter-facility transports, standard settings were initiated and titrated based on clinical assessment of adequate ventilation and oxygenation. In the case of delivery room transports, the Neopuff resuscitator was used with initial standard pressures of $20 / 5 \mathrm{~cm} \mathrm{H}_{2} \mathrm{O}$ and titrated based on chest rise and oxygenation as determined by $\mathrm{SpO}_{2}$ measurements. In the case of inter-facility transport, the transport ventilator was used with initial standard pressures of $20 / 5 \mathrm{~cm} \mathrm{H}_{2} \mathrm{O}$ and titrated based on available blood gases and oxygenation as determined by $\mathrm{SpO}_{2}$ measurements. Both devices have the advantage of delivering set pressures with every breath, decreasing pressure variability. Pressure limits during resuscitation are important. Upton and Milner studied 30 neonates who required resuscitation on whom anesthetic bags with no pressure limits were used in resuscitation, adjusting pressures to achieve chest rise. Tidal volumes rose from $8.7 \mathrm{~mL} / \mathrm{kg}$ early in the resuscitation to $9.7 \mathrm{ml} / \mathrm{kg}$ later in the resuscitation, despite a decrease in the overall median pressure used from $40 \mathrm{~cm} \mathrm{H}_{2} \mathrm{O}$ in early resuscitation to $29 \mathrm{~cm} \mathrm{H}_{2} \mathrm{O}$ in later 
Table 2 Neonates Receiving Mechanical Positive Pressure Ventilation During Inter-facility Transport

\begin{tabular}{|c|c|c|c|c|c|c|c|c|c|}
\hline \multirow[t]{2}{*}{ Subject } & \multirow{2}{*}{$\begin{array}{l}\text { Birth gestational } \\
\text { age (weeks) }\end{array}$} & \multirow{2}{*}{$\begin{array}{l}\text { Corrected } \\
\text { gestational age at } \\
\text { transport (weeks) }\end{array}$} & \multirow{2}{*}{$\begin{array}{l}\text { Transport } \\
\text { weight }(\mathrm{kg})\end{array}$} & \multirow{2}{*}{$\begin{array}{l}\text { Length of } \\
\text { transport } \\
(\mathrm{min})\end{array}$} & \multirow{2}{*}{$\begin{array}{l}\text { Mean PIP on } \\
\text { transport }(\mathrm{cm} \\
\left.\mathrm{H}_{2} \mathrm{O}\right)\end{array}$} & \multirow{2}{*}{$\begin{array}{l}\text { Respiratory rate } \\
\text { total/mechanical } \\
\text { (breaths/minute }\end{array}$} & \multicolumn{3}{|c|}{ Goal tidal volume $4-6 \mathrm{ml} / \mathrm{kg}$} \\
\hline & & & & & & & $\begin{array}{l}<4 \mathrm{ml} / \\
\mathrm{kg}(\%)\end{array}$ & $\begin{array}{l}4-6 \mathrm{ml} / \mathrm{kg} / \\
\text { breath }(\%)\end{array}$ & $\begin{array}{l}>6 \mathrm{ml} / \\
\mathrm{kg}(\%)\end{array}$ \\
\hline 1 & 37 & 37 & 2.97 & 74 & 15 & $96 / 34$ & 16 & 77.0 & 7 \\
\hline 2 & 37 & 38 & 2.90 & 57 & 25 & $103 / 24$ & 42 & 58 & 00.0 \\
\hline 3 & 26 & 26 & 0.92 & 46 & 16 & $44 / 40$ & 00.0 & 11 & 89 \\
\hline 4 & 38 & 38 & 3.01 & 58 & 15 & $89 / 37$ & 3 & 93 & 3 \\
\hline 5 & 33 & 33 & 2.29 & 135 & 2 & $103 / 37$ & 44 & 53 & 3 \\
\hline 6 & 35 & 35 & 1.86 & 46 & 18 & $58 / 38$ & 00.0 & 69 & 39 \\
\hline 7 & 38 & 38 & 3.19 & 104 & 22 & $66 / 35$ & 00.0 & 15 & 85 \\
\hline 8 & 29 & 29 & 1.07 & 214 & 18 & $71 / 32$ & 11 & 63 & 27 \\
\hline 9 & 30 & 30 & 1.26 & 65 & 14 & $82 / 22$ & 98 & 2 & 00.0 \\
\hline 10 & 40 & 40 & 3.44 & 26 & 15 & $102 / 42$ & 69 & 31 & 00.0 \\
\hline 11 & 39 & 39 & 3.20 & 154 & 25 & $44 / 33$ & 1 & 17 & 83 \\
\hline 12 & 39 & 40 & 3.29 & 54 & 15 & $89 / 21$ & 4 & 76 & 20 \\
\hline 13 & 40 & 40 & 3.57 & 48 & 16 & $87 / 32$ & 31 & 67 & 2 \\
\hline 14 & 27 & 34 & 2.06 & 43 & 22 & $73 / 41$ & 72 & 28 & 00.0 \\
\hline 15 & 27 & 35 & 2.18 & 41 & 18 & $75 / 39$ & 20 & 81 & 00.0 \\
\hline Mean & 34 & 35 & 2.48 & 77 & 17 & & & & \\
\hline
\end{tabular}

resuscitation [8]. The study highlights the imprecision in clinical assessments of the adequacy of ventilation and the dynamic changes that occur in this period of transition. Our study demonstrates that even with assurance of delivery of consistent pressures using the Neopuff resuscitator or a set ventilator can deliver high, unpredictable, and greatly varied tidal volumes. Appropriate timely delivery of exogenous surfactant in the delivery room and shortly before transport can magnify the problems of using fixed pressures in a circumstance of unmeasured variable pulmonary compliance.

Lung protection is not the only goal of appropriate ventilation of vulnerable neonates. Cerebral autoregulation is an important protective mechanism against brain injury in critically ill preterm infants [9]. Even brief under- or overventilation with excessive tidal volumes and subsequent hyper- or hypocarbia may place vulnerable infants at an increased risk for brain injury. In our study, 9 of the 14 (64\%) patients in the delivery room transport group were above the target range greater than $50 \%$ of the time, and 8 of those 9 (89\%) were preterm. Hyperoxia further heightens the risk for brain injury in critically ill neonates. This study did not focus on oxygenation, but others have demonstrated that significant hyperoxia was common, even with targeting specific saturations and titrating $\mathrm{FiO}_{2}$ [6].

Increasingly sophisticated in-line measurement tools of lung function have improved management of mechanical ventilation and have become the standards of care in the NICU. Our study contributes to a growing body of evidence that these techniques are a valuable application during intra- or inter-facility transport of neonates. Lilley et al. used respiratory function monitoring during emergency neonatal transport and demonstrated that setting initial ventilator variables by measuring tidal volume and minute ventilation was associated with transcutaneous $\mathrm{PCO}_{2}$ values in the normal range by $15 \mathrm{~min}$ after initiation of ventilation by the transport team in all babies [10].

Certainly, limitations to this study exist. This prospective, observational study had the limited objective of analyzing only the tidal volume of the manual or mechanical breaths provided to the patient, which is in part isolated from the larger clinical situation. The patients, for example, had varying degrees of illness and lung disease with varied respiratory support needs. The majority of the patients had spontaneous contribution to ventilation. Analyzing only the manual or mechanical breaths excluded the possibility that some of the below-range tidal volumes could be the result of inadequate spontaneous respiratory effort. Awake patients with milder lung disease, however, can contribute to the overall volume if spontaneous breath coincide with manual or mechanical inflation. Furthermore, spontaneous respirations contribute to the patient's minute ventilation and can affect the overall under- or over-ventilation.

Our study adds to existing knowledge highlighting the fact that clinical assessment of overall appropriate ventilation is difficult and often inaccurate during emergency neonatal transport and supports the notion that improved monitoring of respiratory function to guide clinical status during transport is necessary. More investigation and implementation are urgently needed. 


\section{Compliance with ethical standards}

Funding; Christiana Care Health Systems Neonatal Research Fund.

Conflict of interest The authors declare that they have no conflict of interest.

\section{References}

1. Auten RL, Vozzelli M, Clark RH. Volutrauma. What Is it, how do we avoid it? Clin Perinatol. 2001;28:505-15.

2. Björklund LJ, Ingimarsson J, Curstedt T, John J, Robertson B, Werner $\mathrm{O}$, et al. Manual ventilation with a few large breaths at birth compromises the therapeutic effect of subsequent surfactant replacement in immature lambs. Pediatr Res. 1997; 42:348-55.

3. Clark RH, Gerstmann DR, Jobe AH, Moffitt ST, Slutsky AS, Yoder BA. Lung injury in neonates: causes, strategies for prevention, and long-term consequences. J Pediatr. 2001; 139:478-86.
4. Garland JS, Buck RK, Allred EN, Leviton A. Hypocarbia before surfactant therapy appears to increase bronchopulmonary dysplasia risk in infants with respiratory distress syndrome. Arch Pediatr Adolesc Med. 1995;149:617-22.

5. Wallin LA, Rosenfeld CR, Laptook AR, Maravilla AM, Strand C, Campbell N, et al. Neonatal intracranial hemorrhage: II. Risk factor analysis in an inborn population. Early Hum Dev. 1990;23:129-37.

6. Tracy M, Downe L, Holberton J. How safe is intermittent positive pressure ventilation in preterm babies ventilated from delivery to newborn intensive care unit? Arch Dis Child Fetal Neonatal Ed. 2004;89:F84-87.

7. Hawkes CP, Ryan CA, Dempsey EM. Comparison of the T-piece resuscitator with other neonatal manual ventilation devices: a qualitative review. Resuscitation. 2012;83:797-802.

8. Upton CJ, Milner AD. Endotracheal resuscitation of neonates using a rebreathing bag. Arch Dis Child. 1991;66:39-42.

9. Volpe JJ. Neurobiology of periventricular leukomalacia in the premature infant. Pediatr Res. 2001;50:553-62.

10. Lilley CD, Stewart M, Morley CJ. Respiratory function monitoring during neonatal emergency transport. Arch Dis Child Fetal Neonatal Ed. 2005;90:F82-83. 